\title{
Adjustment to Geographical Space and Psychological Well-being
}

\section{Thierry Ramadier, Laboratory SAGE, UMR 7363 CNRS/Université de Strasbourg}

Translated from the French by Jean-Yves Bart ${ }^{1}$

\begin{abstract}
$\underline{\text { Abstract }}$
This chapter considers whether individual well-being can be analyzed in the light of both social and cognitive rationales. In other words, it argues that individual well-being might depend on psychological dimensions that do not necessarily relate to constraint (vs. choice), frustration (vs. completing a project) or the physical or economic difficulty (vs. ease) in accessing a resource perceived as indispensible. Instead well-being might be shaped by adjustments to the socio-physical environment, with socio-cognitive processes of appropriation in actions (scripts, routines, etc.) and representations (social dispositions, cognitive schemata, anchorings, etc.) of an environmental context that can be illegitimate (vs. legitimate), unfulfilling (vs. fulfilling), painful (vs. enjoyable), or even impossible (vs. easy) for individuals. It follows that it is not the context of well-being that will be perceived as fulfilling, enjoyable or easy, but the processes of adjustment to that context. This approach to well-being is addressed on the basis of a study of the spatial routines of daily mobility in the city. The concepts of social legibility of geographical space, socio-cognitive accessibility of places and geographical replacement are used to describe and understand adjustments and person/surroundings congruences involved in the well-being of individuals in their relationship to urban space.
\end{abstract}

\section{Keywords}

Well-being, person/surroundings congruence, expectations/chances adjustment, social position, geographical position, cognitive position.

In the introduction to his co-edited volume, Canter (1988 p. 1) argued that "one of the great discoveries that has emerged from the psychological study of the physical environment has been that the human experience of environment is essentially social". A year earlier, Stokols (1987) stressed the importance of the cultural dimension in environmental psychology; twenty years earlier, Lee (1968) sought to connect social relationships to relationships to the physical environment with a "socio-physical" approach. However, the social dimension in environmental psychology has yet to be properly defined; it appears indistinctly related to a social framework (of social relationships) and to a cultural one (of cultural differences in the relationships between signifiers and signified), when it is not reduced to different individual experiences based on different sets of shared material and economic conditions. This chapter discusses the role granted to the social dimension in the analysis

\footnotetext{
${ }^{1}$ This chapter has received support from the Excellence Initiative of the University of Strasbourg funded by the French government's Future Investments program.
} 
of the person/environment relationship with a view towards reconsidering the concept of well-being in environmental psychology.

Social psychology sees the environment as a historical social construct: "The standards of well-being and health have shifted alongside those of moral responsibility. This relativity of prevalent values is neither arbitrary nor predestined, neither erratic nor finalized: it has a meaning. It shows that environmental issues are always raised in a contextualized manner; in other words, they have no intrinsic legitimacy" (Rouquette 2006 p. 13). Environmental psychology, on the other hand, has developed an essentially physical approach of the social dimension (Moser 2009), laying emphasis on the physical presence of individuals and the physical markers of their social attributes (practices, socio-spatial interactions, density, spatial distribution, etc.) or, when absent, through the material traces of their practices (degradation, material appropriation, physical consequences of their practices, etc.), or through arrangements of space as legitimate traces of social practices (architectural and urban development codes and signs). This chapter will show that this physical approach of the social environment is a defining feature of environmental psychology, and has allowed all of its proponents to keep their distance from social psychology and community psychology (Moser 2009). As Bourdieu wrote (2000 p. 110), "technical competence and scientific knowledge function simultaneously as instruments of accumulation of symbolic capital; intellectual conflicts are always also power struggles, the polemics of reason are the contests of scientific rivalry, and so on." Yet there might be a scientific benefit in adopting a cross-disciplinary approach (Ramadier 2014) and combining advances in environmental psychology with those made in sociology and geography, especially when seeking to identify the environmental conditions of well-being (and the lack thereof).

Based on what is arguably the most solid finding in the history of environmental psychology - the congruence between the individual and the environment - this chapter sets out to revisit the place accorded to the sociological dimension in environmental psychology using a tridimensional conceptual model of person/environment congruence. It will end by presenting some examples of research providing illustrations of this model.

\section{1- The role of the social dimension in environmental psychology}

In its earliest stages, environmental psychology initially focused on the physical dimension of the environment, so that the individual's social environment, a core dimension in social psychology that had already existed for fifty years, could be assigned a smaller role in research protocols and conclusions. The first decade of research following Lynch (1960) continued to evidence social variations in relationships to the same geographical space. These studies include works by Hall (1966), Lee (1968), Rapoport (1969) and Canter (1969). This is why Wolhwill (1970) argued that, on the one hand, too few psychologists deigned to support the construction of the new discipline of environmental psychology and, on the other hand, the concept of physical environment was too often perceived as a tool for the study of behavior, being as such of little interest to the psychologist. In the same year, the publication of the first book to include the phrase "environmental psychology" in its title (Proshansky et al. 1970) also contributed to the construction of this research field. In the 1970s, it was the social dimension that became a secondary concern for environmental psychology. Research on the effects of the physical properties of geographical space (from the scale of a room to 
that of the world) on cognitive processes, emotional activities, social interactions and spatial behaviors were extensively investigated. This was made easier by the fact that the legacy of ecological perception theory (Gibson 1966), which was itself derived from Gestalt psychology (Köhler 1929; Koffka 1935), enabled an approach of the construction of environmental meanings (affordances), which was directly based on the physical environment, with no consideration given to the social environment.

The social dimension has never completely disappeared from environmental psychology research; moreover, the duality between the social and physical environment has become recurrent if not cyclical. It was through phenomenology (Lee 1968) that researchers in this field of psychology sought to resolve this tension. At the same time, sociologists, particularly Lefebvre (1968), posited a structural correspondence between physical and social space. The phenomenological approach of environmental psychology suggested emphasizing co-presence and social interactions (Chombart de Lauwe 1974) in order to understand changes induced by the social environment in an individual's relationship to his/her physical environment. In other words, the tension between the social and physical was ultimately resolved by approaching the social environment on the basis of the individual experience of its physical features, leading to an increasingly biological and subjective view of social relationships, to the extent that they became partly obscured. ${ }^{2}$ In this approach, grasping what an individual feels in his/her relationship with others is crucial; in other words, greater emphasis is laid on the individual than on the context. When context is emphasized, social dimensions are often reduced to physical dimensions and/or the subjective dimension of individual reception. Analyses of population density are particularly telling in this respect; the topic was addressed in terms of physical features (over-stimulation of density) and of what the individual feels (crowding). Thus, Stockols (1972) proposes a distinction between "density" and "crowding" so that the researcher can begin by ensuring the salience of population density for individuals. This is an important distinction, but, for instance, in a situation where a politician goes out in a crowd to mingle, it does not tell us the difference between the experience of the politician and that of the people who make up the crowd. In other words, the social positions of all involved are not considered.

From a structuralist perspective, Laborit (1971) proposed an even stronger biological connection between social and physical environment - one that is notably more functionalist than the previous phenomeno-physicalist model. For this author, the physical environment (the city) is only a means of retaining a social structure; physical context only has a functional finality. As a cultural product, the physical environment is an intermediate variable (effector) constructed by the social group (factor), which acts on the group structure (retroactive effect) that defines its existence. In contrast to Lefebvre's approach, this systematic approach does not envisage a direct correspondence between the physical and social environment. By considering the physical environment as one of the means for a social group to maintain its structure, the author lumps the individual in with the physical environment instead of looking at them as two connected entities. Laborit constructed a closed system whose dynamic ultimately lies in the search for an internal point of equilibrium, reached only when goals are matched by the means used to achieve them. In this system, well-being is merely the consequence of the sound functioning of the social structure as a whole. The social structure is perceived as an aggregation of individuals, more or less consciously concerned with the conservation

\footnotetext{
${ }^{2}$ For instance, Holahan (1982 p. 3) described environmental psychology as "an area of psychology whose focus of investigation is the relationship between the physical environment and human behavior and experience."
} 
of a structure that transcends them and in which they are participants. While, as shown below, wellbeing has something to do with the adjustment between social and physical structures, are we for that reason a component of a compact, entirely conservation-oriented social structure, or are we the product of a social structure that follows an indeterminate trajectory, encouraging us to reproduce actions, tastes and thoughts so that our acquired behaviors structure our future experiences?

As noted earlier, numerous theoretical models concerning the relationships between physical and social environment were constructed during the founding stages of environmental psychology. Two main streams of thought strongly and durably influenced environmental psychology. Derived from the Gestalt theory, the first is based on experimentation and a holistic approach. Works on environmental affordance (Gibson 1977) are the main theoretical basis for this research; they contributed to the emergence of the concept of person/environment congruence based on a physicalist concept of the environment. Kaplan (1983) then identified contemplation as an important component of congruence (in addition to knowledge and perceptions, constraints or required behaviors, and projects or intentional behaviors). He went on to argue that some environments (mainly so-called "natural" environments) enable "restorative" experiences by reducing environmental stress and cognitive fatigue, as they offer the opportunity to take a step back from cognitive and behavioral sources of stimulation. Affordance and the restorative character of environments are now considered two dimensions of environmental well-being. The second stream of thought is derived from ecological psychology and relies on observation and experimentation in the field. It was inspired by Lewin's studies (1936) on the concept of field and by Barker's (1968) methodological efforts to take psychology out of laboratories with the concept of behavior setting. Bronfenbrenner (1979) built on this line of research to propose an ecological model of human development based on a set of interacting systems (onto-, micro-, meso-, exo-, macro-systems ${ }^{3}$ ).

Lynch's work on the image of the city (1960) had a tremendous impact on environmental psychology, arguably because his research was situated at the intersection of these streams of thought: like affordances, the concepts of legibility and imageability are based on Werner's "signal objects" (Niveleau 2006) and like behavior settings, on fieldwork serving as a cognitive and behavioral force field. More broadly, these two streams converge on two key points in environmental psychology. The first is based on the progressive construction of a psychology that may be termed as functionalist, even if it is expressed differently in each stream. On the one hand, the Lewinian action-research approach is a core component of studies focused on changes in behavior or the evaluation of "acceptability", which are mostly concerned with finding means of managing a situation without undermining the social order (Stevens 2011). Consequently, neither the beliefs that shape the formulation of research questions nor the social relationships pertaining to the situation under study are questioned. For its part, the Gibsonian approach lays emphasis on the perception of the utility of objects and spaces; however, it also fails to investigate the social relationships that underlie the construction of the functional meanings perceived. For each of these streams of research, and for environmental psychology at large, variations in the relationship to an environmental context are considered primarily functional. The cognitive processes they discuss are in reference either to the singularity of an individual who projects (project, intention, self-fulfillment) or protects (control, rest,

\footnotetext{
${ }^{3}$ The ontosystem refers to intra-psychological processes and states; the microsystem pertains to the person's close environment; the mesosystem is the locus of interaction between different microsystems (for instance, family and school for a child); the exosystem relates to the broader environment beyond the individual's direct experience; the macrosystem refers to the cultural context that influences all the other systems).
} 
restorative withdrawal) him/herself, or to cultural differences (value and belief systems). Sociocognitive processes resulting from social relationships (legitimacy, social distance, etc.) have only very recently started to be addressed by environmental psychology, and are not yet perceived as relevant in identifying the dimensions of individual well-being. The second intersecting point between these two streams of thought, and a core feature of environmental psychology, lies in the concept of congruence (fit, adaptation, compatibility, etc.). The Gibsonian approach is strongly influenced by the Gestaltist idea of a fit between cognitive and physical structures. The same applies to Barker's behavior setting; his works have also contributed to the emergence of environmental psychology.

\section{2- Person/environment congruence and well-being}

The concepts of congruence, and especially of adjustment, have played a crucial part in the theoretical development of environmental psychology and in work on well-being. Moser (2009) wrote that the goal ultimately pursued by environmental psychology consists in defining and identifying the conditions of individual well-being, insofar as the latter "cannot be independent from territorial roots" (p. 240) and as threats to well-being are "situations of concern for environmental psychology" (p. 132). In connection with quality of life, a condition "enabling the individual to fulfill his/her own needs" (Uzzel and Moser 2006), he defines well-being as an objective situation of weak exposure to a nuisance and a subjective situation of weak expression of discomfort, reflecting the congruence between individual and physical environment. Thus, "the state of well-being, of "congruence" or of psychological adjustment between the individual and his/her environment, sets in when the qualities of the context concur with his/her goals and sensitivity to certain environmental qualities" (Moser 2009 p. 93). However, here "congruence" also hinges on a specific acceptation of social environment and its relationship with physical environment. A brief overview of the development of the concept will help understand its impact on environmental psychology. First, it is worth mentioning that the success of cognitive dissonance theory (Festinger 1957) in social psychology probably had an impact on this conceptualization of congruence in environmental psychology, and that the principle of lessening induced psychological tension implicitly relates to the concept of psychological well-being. The concept of congruence appeared even earlier with the Stroop effect (1935) and the congruity or incongruity between the meaning and the shape of a word.

The first environmental sketches of the congruence concept came in the wake of studies in ecological psychology and of the behavior setting concept (Barker 1968). Edney (1976) then developed the idea of a "behavior/environment congruence" to analyze the relationship between a behavior and a given setting. The notion of behavior setting is relevant insofar as the behavioral standards of a place are effectively implemented. Yet this concept reflects a deterministic view of a place's impact on behavior. Wicker (1973) also used the concept of congruence but, unlike Edney (1976), he built on Barker's work and referred to a social determinism of behavior and environment. In other words, behaviors and surroundings are congruent because the two entities are socially determined: as places are constructed according to the behaviors projected in them, behaviors are effectively guided by standards that are objectified in space. However, not every individual is able to participate in the construction of such a site. This type of congruence between behavior and surroundings is also the result of a range of psychological mechanisms, such as operant learning, observational learning, environmental perception and social exchange (Wicker 1979). Congruence as adjustment between behavior and the physical features of the environment is also called "synomorphism" in ecological 
psychology. As with the concept of affordance, the early versions of congruence referred to what the environment evokes from the individual - they did not consider the future, but focused on past experiences. At the behavioral level, congruence refers to necessary actions prescribed by the environment on the basis of individual and collective experiences rather than to purposive actions coming from the individual (Kaplan 1983). At the social level, it pertains to the construction of norms reified by spatial categories. Those coming from the conceptors, and as such endowed with legitimacy, are rarely connected with those coming from the users; the latter are generally considered learners who have mastered - or failed to master - ways of behaving and thinking about their physical environment. As the social dimension is given the cultural status of a general framework that is automatically related to the physical configurations of space, the social impacts of the person/environment convergence are overlooked. As a result of this, psychological issues, such as the control and appropriation of the environment, are also studied independently of social issues (legitimacy, power, etc.).

Stokols (1978) argued that cognitive control of the environment underpins the concept of congruence, in the sense that it allows individuals to carry out planned actions and achieve goals that are important to them, whereas another concept developed by the author, salience, relates to the fact that the environment is associated with goals or psychological needs that matter to the individual (housing, work, leisure, etc.). These two concepts involve references to the quality of the environment and the individual's well-being. They are considered by the author as environmental dimensions defined by the subject. Both result from the interaction between the features of the individual and the environment; their combination enables an evaluation of the quality of that environment. In other words, a functional approach to congruence introduces the concept of need by giving it a bio-psychological character rather than a socio-psychological one, when the three dimensions taken simultaneously would yield useful findings. This utilitarian approach to congruence ultimately favors the concept of quality of life understood as a setting that allows individual needs to be fulfilled.

Michelson (1976), for his part, made a distinction between two forms of congruence. The first reflects the qualities of the environment that fit the individual's goals; the second concerns the individual's representation of this adjustment between environment and behavior. He also proposed a functionalist approach to congruence, defined as a cognitive, affective and behavioral state reached by the person/environment system when the characteristics of the environment allow individuals to fulfill their needs and carry out their activities (Michelson 1980). This state of congruence is achieved through a process of optimization. Yet, in this case, it would again be worth considering the person's social position or trajectory, their spatial position (socio-spatial category of the environment) or even their geographical trajectory (residential, occupational, consumer, etc.) in order to have a better grasp of this optimization process between individuals and surroundings.

Kaplan (1983) includes the concept of congruence in the broader person/environment compatibility model. This model describes the environment as supportive of all activities of individuals, cognitive or behavioral, when the person/environment congruence is appropriate. Conversely, the environment becomes a constraint when this congruence does not exist. It is not the absence of some features in an environment that is problematic, but their presence, which prevents individuals from finding support for their activities (noise, confusion due to the illegibility of the environment, etc.). Based on this model, Kaplan claims that the environment fulfills a specific 
function of support/constraint, which significantly affects the individual's relationship with his/her environment. In other words, he suggests analyzing the quality of the person/environment interface to describe and explain the individual/surroundings relationship better. At the behavioral level, he takes stock of both the approaches of ecological psychology and symbolic interactionism in psychology. To this end, he makes a distinction between behaviors required by the environment and deliberate behaviors - intentional or associated with goals - such as purposive actions and projects. However, some individual intentions, which he calls "inclinations", do not only have behavioral implications. The quality of the person/environment interface does not only depend on the behaviors envisioned by the individual; it also depends on the organization of information resulting from cognitive processes implemented to elaborate and structure the environment represented on the basis of the physical surroundings. The author mentions the perceptive and representative processes traditionally addressed in environmental psychology, but he also adds a new category of processes derived from the concept of inclination. By granting the status of cognitive mechanism to this concept, he asserts that it encompasses a range of processes related to "contemplation" and "reflection". These processes, he argues, enable the organization of thought and feelings related to the environment by selecting and processing information stored in the memory: "Reflection is a means of extracting information from the past and anticipating possibilities in the future" (Kaplan 1983). This time the temporal dimension is a key element of congruence.

Kaplan notes that these processes have rarely been investigated, mostly because anthropologists concealed their importance by stressing the fact that evolution processes occurred under pressure. He suggests that in the event of incompatibility between the various activities described (required action, purposive action and inclination, environmental perception and knowledge, and reflection), an order of priorities occurs, with action and the environment favored over cognition and individual aspirations, in order to maintain a sufficient degree of adaptation and avoid inaction. Therefore, reflection is the last activity required in the case of incompatibility; in the case of compatibility, the four types of activity are pursued in parallel.

If one considers that, through an optimization process, the person/environment relationship leads towards a state of congruence or compatibility, one needs to look beyond the instrumental aspects of this relationship. According to Stockols (1990), who echoed Canter's introductory remark (1988), theoretical models in environmental psychology have made steps in that direction. In addition to the minimal approach, which neglects environment-induced changes to practices and social interactions, scholars have successively developed an instrumental and a "spiritual" approach to the person/surroundings relationship (Stockols 1990). In the latter, the environment is studied as a physical and social context laden with meanings: through the diversity and complexity of meanings, the environment becomes supportive for the individual's well-being or lack thereof. In the past two decades, emphasis has been laid on the socio-cultural and symbolic aspects of the environment and of the person/environment relationship, in which the instrumental approach saw the environment solely as a means of pursuing a wide array of individual activities. The role of surroundings in social relationships deserves further investigation.

3- Social interaction, cultural contrasts or social relationships: three approaches to social facts 
The teleological approach to well-being and quality of life has the benefit of being easily compatible with the econometric models of human behavior. The concept of utility in economics - or preference in environmental psychology and competence in ergonomic psychology - is part of the construction of a now multi-disciplinary (economics, psychology, sociology, geography, etc.) rational model of human behavior. Even if this rationality is limited (Simon 1947), including by the individual's subjective perceptions (Tversky and Kanhman 1981), it is chiefly an approach where the individual constructs him/herself based on his/her sensibilities and interactions with the world. This perspective rests on an internal/external duality; in other words, on the opposition between objectivity and subjectivity and their possible congruence. This is why, in rational models, the social environment is only seen as an outside element, like the physical environment. Approaches focused on needs overlook the fact that both individuals and geographical space are also the product of social relationships that do not only manifest themselves through cultural differences. In other words, differences in social relationships are not necessarily cultural; they are also shaped by structural asymmetries. For instance, more differences might be observed between an employee and a CEO of a corporation regarding their tastes and relationships with the environment than between a Thai and a French CEO or a Spanish and a German employee (though this does not mean we should neglect cultural differences, which can cause misunderstandings and discomfort - see, for instance, the cultural dimension of proxemics evidenced by Hall in 1966). At the individual level, social relationships are not stable; they are embedded within force fields (Lewin 1936) and fields of struggle (Bourdieu 1984). Due to these struggles, beliefs, norms and ideologies are not only constructed within groups, but also through the relationships and interactions between these social groups. For this reason, knowledge of the social, geographical and psychological positions of individuals is crucial to gaining an understanding of the person/environment congruence - and so is knowledge of social relationships. The social environment cannot be reduced to the quality of copresence or the experiential quality of the individuals' relationship networks (whether their relationships are positive or not, fulfilling or not, conflict-laden or friendly), i.e. to immediate interactions or those that individuals may assess subjectively. Even in environmental psychology, the stakes of conflict and co-operation, and the engagement in the game that they encourage, matter just as much as conflict and co-operation themselves. For instance, can we truly understand why some people remain happy living in a neighborhood that has a bad reputation when others are unhappy, if we fail to see that the former do not have any hopes for better living conditions as they consider themselves to have reached the apex of an ever-improving residential trajectory, whereas the latter, who sometimes come from the same neighborhood and have achieved upward social mobility thanks to their degrees, aspire to live in a neighborhood where they can more easily selfidentify as residents? Why should the prospect of a visit to the presidential palace be more anxietyinducing for a teacher than for a doctor or a lawyer? Is this merely about being accustomed to such physical environments (even though a teacher may already have attended official receptions at city hall)? Is it about perceived hierarchical differences? Or is it because this situation appears to him/her to be very unlikely and unprecedented (this dimension may be objectivized by measuring the respective probabilities of a teacher, a doctor and a lawyer pursuing a political career)? These are all probably combining factors. However, by formulating it in this way, we are not referring to a difficulty relating to cultural differences or to a lack of familiarity with the physical and social environment (the first example shows that familiarity with the environment is not necessarily an asset), but rather a disconnect between environmental expectations and the objective chances of finding oneself in the expected environmental setting. This brings us back to the concept of 
congruence, but this time with less emphasis on the characteristics of the physical environment and on the individual's supposed needs. Likewise, the opposition between objectivity (or exteriority) and subjectivity (or interiority) is not as central here. This is a socio-cognitive form of familiarity rather than an experiential one. It depends on the relationship between expectations and chances, in which each entity is constructed on the basis of the other: environmental expectations (for instance, considering setting up an office in a room of a city center apartment) are adjusted to the individual's chances of meeting them (which are higher for a university professor than for a schoolteacher, even though both may live with a partner and children and need to work from home). In their study of the failure of prophecy, Festinger et al. (1956) also observed that expectations are adjusted to chances: expectations are remodeled, at least in their meanings, on the basis of the facts that shape the chances of them being met. Bourdieu (2000) added that when an individual's most fundamental expectations cannot be adjusted to the chances of meeting them, the hopes they formulate can become utterly unrealistic. For instance, people in very poor housing conditions often claim in interviews that they would like to live in the city's well-off neighborhoods. Likewise, overall assessments of residential situations always report high rates of satisfied individuals (around $80 \%$ ): in this case, everything happens as if expectations are adjusted to the objective chances of fulfilling them, and as if these chances ultimately reflect the current environmental situation.

This perspective appears well suited to the study of the environmental well-being of individuals. In this sense, I concur with Moser's claim (2009 p. 241) that "environmental psychology must move beyond an instantaneous vision of the man-environment relationship". However, this study will not use the concept of time as a dimension situated outside the individual, instead considering the individual's social and environmental trajectory. In other words, time is inscribed in practices (Bourdieu 2000) and it is "really experienced only when the quasi-automatic coincidence between expectations and chances [...] is broken" (Bourdieu 2000 p. 208). Likewise, emphasis will no longer be laid on the individual's tangible, direct social environment (though it will not be neglected, as research on attachment to places shows the importance of the networks formed there), but rather on the positions and socio-cognitive stakes for the person; in other words, social relationships that are not limited to social interaction and physical co-presence (Ramadier 2007).

\section{4- A tridimensional theoretical proposal}

To sum up the state of the art on the role of the social dimension in environmental psychology, one might say that economic utility (needs, preferences and functionality) cannot be the only way of addressing the concept of individual environmental well-being. This is especially so as it has major drawbacks: either it assumes the needs of individuals (generally on the basis of needs considered universal) or, as is more frequent in psychology, when respondents are considered able to make their own informed decisions, researchers take the meanings of practices for the determinants of these practices (Beauvois 1994). Sociological (not social) and psychological utility, i.e., the relation between the conditions of possibility of a practice (what is possible for me to do?) and the way of experiencing the world in practice - action or representation- (what do I do or what can I consider doing?), provides a way out of this impasse. These two questions no longer relate to an opposition between subjectivity and objectivity: each can be addressed in a way that sheds light on how individuals 
construct themselves (subjectivation processes) and how practices and their context are constructed (objectification processes).

The social representations paradigm of environmental psychology has partly supported this functionalist approach to the person/environment relationship. While Milgram and Jodelet (1976) developed this psychosocial approach in a study of urban space, environmental objects of research have since become more diverse. However, all studies based on this paradigm also posit that representations are forged within the group through interaction between members. Relationships between groups are not perceived as relevant to the analysis of the social construction of an object. Everything happens as if social psychology applied to the environment is also subject to the fundamental attribution error (Ross et al. 1977) and the norm of internality (Jellison and Green 1981) that it enabled researchers to evidence. In fact, numerous experimental studies have shown that we more readily attribute the cause of an event to the characteristics of those involved in it than to the context (fundamental attribution error); as this explanation of facts is learned socially, it is also applied to individuals (norm of internality). In other words, both theoreticians in psychology and survey respondents have a very hard time moving beyond this opposition between internality and externality. Yet, a representation of an object can perfectly well be developed within a group, but according to its relationship to other groups rather than regardless of it. The first environmental psychology study linking social group and social positions dates back to the 1980 s, when Deschamps and Doise (1988) investigated the representations of school among children born to Swiss and migrant parents. It reported no difference between the two groups of children regarding their representations of how school works and how they envisage what they will do after school; however, insofar as the socio-spatial setting of each group was different and as these differences were also correlated with the social positions of their parents, their representations of their mother tongues, regions of origin and of the places where they considered working after completing their studies all differed. While the two groups were sociologically similar in some aspects, the children of migrant parents had representations of the institution that matched those of Swiss parents; the parents' social positions most influenced the socio-spatial dimensions of their representations of school.

From a cognitive standpoint, not considering positional level in psychological explanation (Doise 1982) entails using the concepts of individual cognitive, affective and conative competences rather than that of dispositions to act and think. It means retaining the idea of individual self-construction, even if based on social materials, and ultimately thinking that expectations and chances can be similar when competences are similar. It means positing that, from a cognitive and affective point of view, individuals are always potentially interchangeable (which happens to reinforce the naturalistic idea that fundamental differences are ultimately of a biological nature). This universalist vision of human psychology masks the fact that from the beginning of social and geographical trajectories, the conditions for acquiring all sorts of "competences", including "environmental competences", differ; their appropriation - or even incorporation - make them lasting because with time and repetition, these "competences" are no longer conscious (for instance, we do not think about our movements when we walk, even though we have learned them, and it has become difficult to change them). Does the term "competence" still apply in this case? Other theoretical models, using econometric approaches, use the concept of "preference". Instead of learning, a core feature of their investigation of relationships with the environment is the rational and/or emotional ranking of environmental possibilities by individuals. In other words, in this model, individual expectations determine the chances of a given environmental context presenting itself. This theoretical approach is particularly 
common in environmental psychology, as it fits easily with approaches focused on individual sensibility, by placing more emphasis on expectations than on chances in the relationships with geographical space, and consequently by individualizing the concept of expectation. This theoretical approach also fits well with the "rational choice" concept of econometric models, insofar as preference is always the individual's ranking of a known set of possibilities, whose achievement, without this individual ranking, can be posited as equally probable.

In contrast, the dispositional model of sociology, whose most advanced version was proposed by Bourdieu (1984), posits that our ways of doing, thinking and being are distributed across social space; in other words, they depend on social positions (and trajectories) within that space. Unlike competence and preference, disposition is a socio-cognitive and socio-behavioral scheme, which strongly depends both on the social field to which the individual must adjust (for instance, physical strength is not an indispensible disposition in the academic field, but it is in sports), and on the individual's position within the field (while strength is a pre-requisite for the athlete, this is less the case for the trainer and arguably even less for the club manager). The importance of the individual's spatial position is key in environmental psychology, even if it is ultimately addressed in terms of location rather than position: "The issues faced by environmental psychologists lead researchers and practitioners to inscribe their analyses in spatial and temporal dimensions; concepts of space and place thus occupy a central position" (Moser 2009 p. 19). Position is also a geographical concept. Unlike geographical location, which refers to a single point within an isotopic physical space, geographical position contributes to the construction, structuring and even the analysis of the geographical space under study. Position is a spatial condition that produces differentiation. For instance, the city center cannot be defined without the suburbs and vice versa. Furthermore, this form of spatial categorization necessarily rests on a concentric concept of geographical space. Lastly, insofar as the same object may elicit different socio-cognitive representations, each of these representations can be envisaged as a socio-cognitive position. Indeed, on the one hand, a representation is social because, beyond the social dimensions of its construction, it is shared without being the only one possible: other representations co-exist, to the extent that there is a space of representations for each object. However, the concept of cognitive space or space of representations is conceptualized at the individual level. For instance, Slater (1976) proposed the concept of intrapersonal space, referring to a mental space of sorts, to understand the organization and relationships between the constitutive elements of representations. ${ }^{4}$ Ehrlich (1979) then submitted the concept of cognitive mobility. However, we will see that an analysis of representations of space based on individual social trajectories shows that "cognitive mobility" comes with social mobility (Viaud 2003); in other words, the space of representations or the cognitive space of an object, in line with social representation theory, is not only an intrapersonal space.

Concerning the relationships between geographical, social and cognitive spaces, several studies on non-environmental objects have, however, shown a match between the person's representation and their social position (Tafani and Bellon 2001), and the adjustment of representation to the individual social trajectory (Viaud 2003). These studies are based on the idea that social representations are stances (or psychosocial anchorings) that relate to the positions occupied within the social system of production of values (Doise and Palmorani 1986). Likewise, there is ample evidence that an

\footnotetext{
${ }^{4}$ Portugali (1996), based on the concept of inter-representations network (IRN), refers to this intrapersonal space under the ambiguous term of "cognitive maps".
} 
individual's geographical position has an impact on their representation of space; one has only to compare world maps produced on various continents to observe that each region of reference systematically places itself in the upper central section of the map; this geographical position thereby "displaces" the location of all other areas on the map. Lastly, numerous studies on social segregation in space have shown that spatial positions are associated with social positions. In other words, these different spaces (geographical, sociological and psychological) interact to form a trijection of sorts, to use a mathematical model. Several pairwise correspondences have already been proposed. In sociology, Durkheim and Mauss (1903), then Bourdieu (Wacquant 1992) have long evidenced a correspondence between social and mental structures. In psychology, the "Geneva school" of social representations (Doise and Lorenzi-Cioldi 1989) has reached the same conclusions. Sociologists from the Chicago school were the first to demonstrate the correspondence between social and geographical space based on their studies on socio-spatial segregation. Examinations of the correspondence between mental and geographical structures, launched with a study by Lynch (1960) on the images of three US cities, were early landmarks in environmental psychology. Here I have devised a tridimensional model of the person/environment congruence (Figure 1) that introduces social space into the correspondence between geographical and mental space; thus, the sociocognitive space is no longer limited to an intrapersonal space; cognitive position is associated with a social and geographical position drawn from all possible socio-spatial representations.

Figure 1: Tridimensional model of person/environment congruence

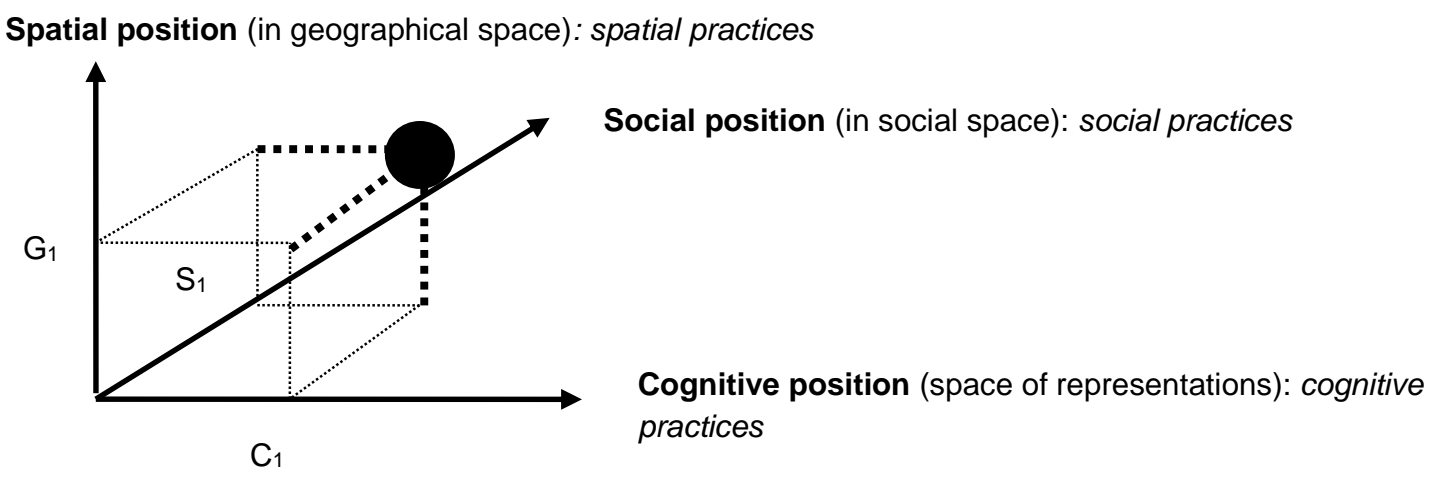

5- A few examples illustrating tridimensional congruence applied to the urban environment

The tridimensional (geographical, sociological and cognitive) congruence model was progressively devised on the basis of studies that aimed to show that the legibility of urban space was not only physical (Lynch 1960), but also socio-physical (Ramadier and Moser 1998). An analysis of foreign students' representations of Paris (Ramadier 1997) clearly showed that differences observed between the European sample and the sub-Saharan African sample had nothing to do with individual 
cultural differences, being rather related to the congruence (or lack thereof) between the cultural characteristics of buildings (signs and architectural or urbanistic codes of geographical space) and the dispositions acquired by the student (signs and architectural or urbanistic codes internalized, making up the cultural capital of relationship to urban space). The difficulty in making Parisian space legible (constructing a spatially consistent and unified representation of the city) was only temporary for some of the less-adjusted students and more lasting for others. On the other hand, the betteradjusted socio-spatial relationships enabled individuals to transfer their ways of representing the city and to move within it immediately upon arriving. While from a cognitive standpoint, the nonadjustment between people and surroundings showed that the difficulty in representing urban space derived from a difficulty in making geographical space legible in its physical, social and functional dimensions and forced individuals to focus on their use of space (egocentric function), from an affective standpoint, many of those who struggled with this also reported difficulties in travelling, fear of getting lost and in some cases a form of "homesickness" - thus, such experiences of urban space were connected to a decrease in everyday mobility (Ramadier 2009). In sum, the relationship to urban space is not a simple matter of competences to acquire, but instead primarily relies on dispositions that can be transferred from one geographical space to another, thanks to the sociocognitive proximity of the two places for the individual. This may be termed as socio-cognitive accessibility to the place of destination (Ramadier and Enaux 2012). The possible evolutions of these dispositions show that so-called "cultural" differences pertaining to cognitive mapping cannot be ascribed to different "cognitive styles" (Evans 1980) but to socio-cognitive processes that remain to be determined. This leads to the following research question: which social and cognitive conditions favor individual socio-cognitive adjustment to a new urban space when this adjustment cannot be made through the transfer of already internalized dispositions to read geographical space ${ }^{5}$

More recent research (Dias and Ramadier 2015) has shown that representations of urban space depend on individual social trajectories. When social positions (managers) and areas of residence are equal, representations of urban space differ according to whether the individuals' parents were already managers (stable social mobility) or had intermediate socio-occupational positions (downward social mobility). ${ }^{6}$ Likewise, people who occupy intermediate socio-occupational positions but whose parents were managers (downward social mobility) also have socio-cognitive representations of space that differ from the other two groups. In other words, inheriting, acquiring or losing the position of manager affects the spatial representation of the city. Primary socialization (in childhood) is therefore not singlehandedly responsible for forging social dispositions to read urban space. Secondary socialization (social integration through professional activity) is also important. Yet, these findings also confirm that socialization and individualization are not opposite processes; individuals vs. society is not as well-founded an opposition as is often thought (Elias 2010).

Other recorded geographical facts confirm the strong relationship between cognitive and geographical dimensions in relation to space. Spatial practices are more frequently investigated than spatial representations. A study, also conducted in a residential area of the nearby suburbs of Strasbourg, has shown that decisions pertaining to weekly mobility patterns are characterized by the

\footnotetext{
${ }^{5}$ In the same way that someone who has learned to read may sometimes not be able to read on a regular basis or understand a text.

${ }^{6}$ It is worth remarking that, as these social trajectories are partly influenced by the social history of the residential area under study (which has experienced progressive gentrification since the 1990s), the ages of respondents vary according to the social trajectories observed.
} 
dominance of spatial routines. For example, $70 \%$ of all weekly mobility patterns ${ }^{7}$ concern activities that no longer require decisions or choices regarding the place of destination - they are routine (Table 1). ${ }^{8}$ This geographical stability is not specific to our research: the Canadian research protocol that inspired the aforementioned study (Ramadier et al. 2005) yielded similar findings about the spatio-temporal distribution of this daily mobility pattern.

Table 1: Raw occurrences of spatio-temporal decisions for daily mobility patterns within a week $(n=74)$

Type of decision in: $\quad$ space

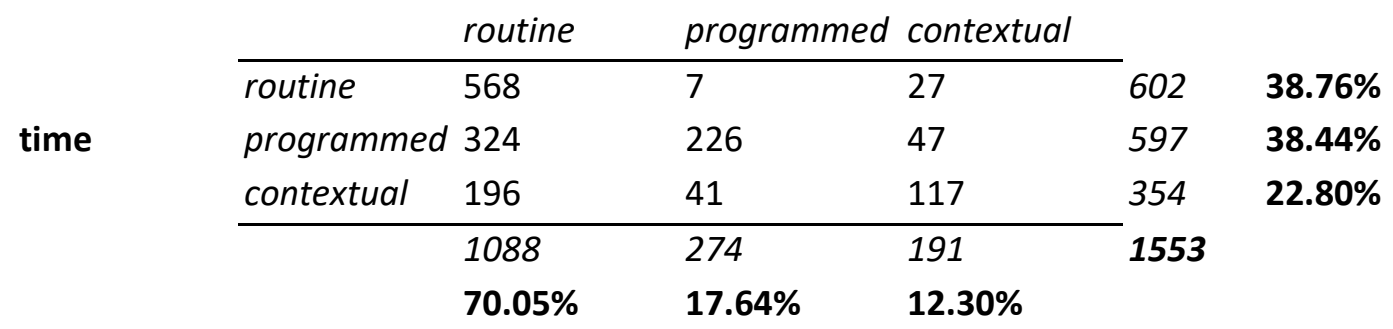

These findings cannot be attributed to massive amounts of necessary mobility patterns like home/work commutes, as they are somewhat similar for pensioners in the same sample (Table 2):

Table 2: Raw occurrences of spatio-temporal decisions for daily mobility patterns within a week for pensioners $(n=22)$

Type of decision in: $\quad$ space

\begin{tabular}{|c|c|c|c|c|c|c|}
\hline & & routine & programmed & contextual & & \\
\hline \multirow{5}{*}{ time } & routine & 111 & 3 & 5 & 119 & $28.40 \%$ \\
\hline & programmed & 105 & 74 & 21 & 200 & $47.73 \%$ \\
\hline & contextual & 63 & 10 & 27 & 100 & $23.87 \%$ \\
\hline & & 279 & 87 & 53 & 419 & \\
\hline & & $66.59 \%$ & $20.76 \%$ & $12.65 \%$ & & \\
\hline
\end{tabular}

These results show that our geographical positions are particularly stable. Yet this geographical stability is not only cognitive (decisional), it is socio-cognitive insofar as not all spatial routines have the same intensity for all practices. It is also spatio-cognitive insofar as, as Feldman (1990) demonstrated regarding residential mobility, daily mobility patterns are also based on the continuity between the geographical features of the places of departure and destination.

On the one hand, only certain activities are associated with routine mobility patterns in time and space. Unsurprisingly, for respondents who are employed, the bulk of home/work mobility patterns

\footnotetext{
${ }^{7}$ Seventy-four respondents from a residential area of Strasbourg built in the 1950s-1960s were asked to write down their mobility patterns during a seven-day period; information was collected from them every 48 hours by phone.

${ }^{8}$ Programmed mobility patterns are those for which a choice is made between possible destinations accessible to the individual and for which decisions do not depend on the current context but on a more general spatio-temporal organization. Contextual mobility patterns are those that are neither routine nor programmed.
} 
are spatio-temporal routines. Taking the children to school or to extra-curricular activities, taking walks, going to the bakery, to an art class or to a place of worship are the most routine activities both in space and in time.

As the spatio-temporal stability of mobility patterns depends on the activity, unsurprisingly we observe differences between social groups - for instance, between managers and employees. Within the same sample of Strasbourg residents, taking the children to school, taking walks, going to do sport, to a class or to a place of worship are spatio-temporal routines that are more specific to employees; going to the bakery, to the hairdresser, to an art class or taking the children to an extracurricular activity are routines more often observed in managers. In other words, both the spatiotemporal relationships with activities and the activities themselves involve socialization.

On the other hand, the analysis of the Strasbourg household travel survey carried out in 1999 by the National Institute of Statistics and Economic Studies (INSEE) in 1999, with a representative sample of frequented places (Ramadier et al. 2011), showed that a significant part of daily mobility patterns are between geographically similar positions. In $1999,36.29 \%$ of the daily mobility patterns of the residents of Strasbourg's historic city center showed the destination to be another neighborhood ${ }^{9}$ of the historic city center; $27.32 \%$ of the mobility patterns of the residents of the part of the city center built during the so-called German period (1870-1914) were to another neighborhood in that sector; $21.49 \%$ of the mobility patterns of the residents of the former villages that are now part of Strasbourg's urban area (the old towns of Schiltigheim, Cronenbourg, etc.) were to another one of these sectors; residents in large housing developments more often travelled to the other large housing developments than elsewhere ( $13.89 \%$ of their daily mobility patterns): the mobility patterns of the other residents only proved to be between 2.19 and $8.81 \%$ in such places, even though a major shopping center is located in one of these neighborhoods. However, the more central the place of residence, the more similar to it are the destinations.

Overall, these findings suggest that these daily mobility patterns are in part replacements (Ramadier 2010), in that individuals cross the functional borders of geographical space without crossing any social and cognitive borders. This also shows that daily mobility might contribute to reinforcing social segregation in space, which is already strongly structured by residential mobility.

\section{6- Conclusion}

Since environmental psychology considers well-being, it cannot content itself with addressing the environment as an external constraint to which individuals adjust themselves, or as a means of adapting the material dimensions of physical and social environment to individual preferences and inclinations, or even to simply combining the two approaches by emphasizing the complexity of the regulations leading to the person/environment congruence. This approach, which is based on a dichotomy between inside and outside and between the objectivity and subjectivity of facts, systematically falls into the trap of the opposition between the individual and society. This entails that the adjustment of the individual's relationship to the environment is at the service of a general balance of human relationships on the scale of society (Elias 2010). This functionalist and

\footnotetext{
${ }^{9}$ For the purposes of the study, the "neighborhoods" are the smallest spatial units in the nomenclature of the French National Institute for Statistics (INSEE) - called in French llots Regroupés pour I'Information Statistique (IRIS)
} 
homeostatic vision of the relationship to the environment and of social relationships precisely neglects social, cognitive and geographical structures. It describes relationships between individuals, groups and places as symmetrical. Either the objective properties of individuals, groups and places or the subjective perceptions of individuals (preferences) or groups (cultures) differ. As the individual is perceived as a self-constructing actor within a group and an environment, adjustments to the environment and of the environment are generally studied using the concept of control rather than of power. For instance, is it because an adolescent can close his bedroom door that he is free from his parents' authority and demands? Symmetrically, with the concept of affordance, places are perceived as regulators of human behavior - as controllers. Yet, for instance, in a classroom, the desk that faces all the others, which is conventionally attributed to the teacher, can be used by a student when the professor is absent, and the student may in turn profit from the symbolic value of this geographical position in the class. In other words, asymmetrical relationships of domination, of legitimacy of certain values or beliefs, or between certain places in a given socio-cognitive and geographical context, are rarely considered in environmental psychology. Social relationships are often reduced to the physical co-presence of individuals. Nevertheless, the environmental well-being of an individual is also constructed with social and spatial recognitions, feelings of social and spatial justice, more or less strong identifications with the groups and institutions that manage given places, etc. The trials of adjustment owing to the cost of entry to certain places, to incentives to visit or avoid them, etc. can be powerful barriers to psychological, social and physical well-being. For these reasons, I have proposed a (dis)positional model in which social, geographical and cognitive dimensions are based on the same concept of position (and consequently of social, cognitive and geographical space), in order to grasp processes of person/environment congruence involved in individual well-being jointly and simultaneously, without favoring any one of the three dimensions over the other.

While well-being cannot be limited to individual experience, it cannot either be reduced to rigid structures that automatically have effects. There is no way of knowing if statistical frameworks will apply to a given individual. However, the fact remains that individuals have a personal experience of these frameworks that can only be perceived on the basis of statistical probabilities by researchers; social realities can also be invested in an individualized form. Therefore, at the level of the individual, this statistical framework is a dimension of a living environment that is not as physical and tangible as that which environmental psychologists usually refer to as a "living environment". In fact, the adjustment of the individual's expectations to their chances of fulfilling these expectations constitutes a physical, social and cognitive framework that appears to have an impact on the place of residence, the way of inhabiting places, of representing the city and travelling, etc. This sociocognitive set of references in the relationship to space is as evident to the individual as his/her family name or mother tongue. For instance, it is easier to speak a language when the chances of encountering other speakers of that language are adjusted to the expectations of being able to speak it freely. While the tridimensional model of well-being reveals that entre-soi can in some cases reflect a logic of person/environment congruence at the service of well-being, it also shows that it is a social, cognitive and geographical construction and not a natural human inclination (objectivity) or even a natural inclination of some individuals (subjectivity), and even less a necessity for the person's wellbeing. Socio-cognitive adjustment to space, as a construction that defines the individual's expectations according to the chances of fulfilling them and vice versa, is ultimately a model that opens up a great many possibilities. Indeed, the individual's trajectory in a field of forces and of 
struggles on the scale of society (the social space) redefines the framework of expectations and possibilities at each instant.

\section{References:}

Barker, R. G. (1968). Ecological psychology: concepts and methods for studying the environment of human behavior. Stanford, CA: Stanford University Press.

Beauvois, J-L. (1994). Traité de servitude libérale. Analyse de la soumission. Paris: Dunod.

Bourdieu, P. (1984). Distinction: A Social Critique of the Judgment of Taste. Cambridge: Harvard University Press.

Bourdieu, P. (2000). Pascalian Meditations. trans. Richard Nice, Palo Alto: Stanford University Press.

Bronfenbrenner, U. (1979). The Ecology of Human Development: Experiments by Nature and Design. Cambridge, MA: Harvard University Press.

Canter, D. (1969). An intergroup comparison of connotative dimensions in architecture. Environment and Behavior, 1, 37-48.

Canter, D., Correira Jesuino, J., Soscka, L., \& Stephenson, G. M. (Eds.) (1988). Environmental social psychology. London: Kluwer Academic Publishers.

Chambart de Lauwe, P-H. (1974). Eth(n)ologie de l'espace. In De l'espace corporel à l'espace écologique. Symposium de l'Association de Psychologie Scientifique de Langue Française. Paris: PUF.

Deschamps, J-C., \& Doise, W. (1988). Similar or different? Young immigrants in the Genevan educational context. In D. Canter, J. Correira Jesuino, L. Soscka, \& G. Stephenson (Eds.), Environmental social psychology. London: Kluwer Academic Publishers.

Dias, P., \& Ramadier, T. (2015). Social trajectory and socio-spatial representation of urban space: the relation between social and cognitive structure. Journal of Environmental Psychology, 41, 135-144.

Doise, W. (1982). L'explication en psychologie sociale. Sociologies. Paris: Presses universitaires de France.

Doise W., \& Palmonari, A. (1986). L'étude des représentations sociales. Neuchâtel: Delchaux \& Niestlé.

Doise, W., \& Lorenzi-Cioldi, F. (1989). Sociologues et psychologie sociale. Revue Européenne des Sciences Sociales, 27, 147-196.

Durkheim, E., \& Mauss, M. (1903). De quelques formes de classification. Contribution à l'étude des représentations collectives. Année Sociologique, 6, 1-72.

Edney, J. J. (1976). Human territoriality. Psychological Bulletin, 81, 959-975.

Ehrlich, S. (1979). La mobilité cognitive, Bulletin de psychologie, $\mathrm{n}^{\circ} 340$, tome 32 (8-14), 413-423.

Elias, N. (2010). Au-delà de Freud: sociologie, psychologie, psychanalyse. Paris: La Découverte, 2010.

Evans, G. W. (1980). Environmental cognition. Psychological Bulletin, 88(2), 259-287. 
Feldman, R. M. (1990). Settlement identity: psychological bonds with home places in a mobile society. Environment and Behavior, 22(2), 183-229.

Festinger, L., Riecken, H. W., \& Schachter, S. (1956). When Prophecy Fails: A Social and Psychological Study of A Modern Group that Predicted the Destruction of the World. Harper-Torchbooks.

Festinger, L. (1957). A theory of cognitive dissonance. Palo Alto: Stanford University Press.

Gibson, J. J. (1966). The Senses Considered as Perceptual Systems. Boston: Houghton Mifflin.

Gibson, J. J. (1977). The Theory of Affordances. In R. Shaw \& J. Bransford (Eds.), Perceiving, Acting, and Knowing. Hoboken, NJ: John Wiley \& Sons Inc.

Hall, E. T. (1966). The hidden dimension. New York: Doubleday.

Holahan, C. (1982). Environmental psychology. New York: Random House.

Jellison, J. M., \& Green, J. (1981). A self-presentation approach to the fundamental attribution error: The norm of internality. Journal of Personality and Social Psychology, 40(4), 643-649.

Kaplan, S. (1983). A model of person/environment compatibility. Environment and Behavior, 15(3), 311-332.

Kaplan, S. (1992). The restorative environment: nature and human experience. In D. Relf (Ed.), The role of horticulture in human well-being and social development (pp. 134-142). Portland: Timber Press.

Köhler, W. (1929). Gestalt Psychology. New York: Liveright.

Koffka, K. (1935). Principles of Gestalt psychology. New York: Harcourt, Brace \& World.

Laborit, H. (1971). L'homme et la ville. Paris: Flammarion, 1971.

Lee, T. R. (1968). Urban neighborhood as a socio-spatial schema. Human Relations, 21, 241-268.

Lefebvre, H. (1968). Le Droit à la Ville. Paris: Éditions Anthropos.

Lewin, K. (1936). Principles of Topological Psychology. New-York: McGraw Hill.

Lynch, K. (1960). The Image of the city. Cambridge, MA: MIT Press.

Michelson, W. (1976). Man and his urban environment: a sociological approach. Reading, Mass: Addison-Wesley, 2nd ed.

Michelson, W. (1980). Long and short range criteria for housing choice and environment behavior. Journal of Social Issues, 36(3), 135-149.

Milgram, S., \& Jodelet, D. (1976). Psychological maps of Paris. In H. Proshansky et al. (Eds.), Environmental Psychology (2nd edition). New York: Holt, Rinehart \& Winston.

Moser, G. (2009). Psychologie environnementale. Les relations homme-environnement, Brussels: De Boeck.

Niveleau, C. (2006). Le concept gibsonien d'affordance: entre filiation, rupture et reconstruction conceptuelle: Intellectica, 43, 159-199.

Portugali, J. (1996). The construction of cognitive maps. London: Springer. 
Proshansky, H. M., Ittelson, W. H., \& Rivlin, L. G. (1970). Environmental Psychology: Man and His Physical Setting. New York: Holt, Rinehart \& Winston.

Ramadier, T. (1997). Construction cognitive des images de la ville. Evolution de la représentation cognitive de Paris auprès d'étudiants étrangers. Thèse de doctorat, Université Paris-Descartes.

Ramadier, T., \& Moser, G. (1998). Social legibility, the cognitive map and urban behavior. Journal of Environmental Psychology, 18(3), 307-319.

Ramadier, T. (2004). Transdisciplinarity and its challenges: The case of urban studies. Futures, 36(4), 423-439.

Ramadier, T. (2007). Mobilité quotidienne et attachement au quartier: une question de position?, In J-Y. Authier, M-H. Bacqué, \& F. Guerin-Pace (Eds.), Le quartier: Enjeux scientifiques, actions politiques et pratiques sociales (pp. 127-138). Paris: La Découverte.

Ramadier, T., Lee-Gosselin, M., \& Frenette, A. (2005). Conceptual perspective for explaining spatiotemporal behavior in urban areas. In Lee-Gosselin, M. E. H., \& Doherty, S. T (Eds.), Integrated landuse and transportation models: behavioral foundations (pp. 87-100). Elsevier: Oxford.

Ramadier, T. (2009). Capital culturel, lisibilité sociale de l'espace urbain et mobilité quotidienne. In F. Dureau, \& M-A. Hily (Eds.), Les mondes de la mobilité (pp. 137-160). Presses Universitaires de Rennes.

Ramadier, T. (2010). La géométrie socio-cognitive de la mobilité quotidienne: distinction et continuité spatiale en milieu urbain. Université de Nîmes [http://halshs.archivesouvertes.fr/view_by_stamp.php?\&halsid=kh3libj8lvv3c358lmqbgu7mc1\&label=SHS\&langue=fr\&actio n_todo=view\&id=tel-00564812\&version=1)

Ramadier, T., Petropoulou, C., Haniotou, H., Bronner, A-C., \& Enaux, C. (2011). Daily Mobility and Urban Form: Constancy in Visited and Represented Places as Indicators of Environmental Values. In M. Theriault \& F. Desrosiers (Eds.), Geographical Information and Urban Dynamics: Mobility and Urban Form: From Analysis to Simulation (pp. 129-157). ISTE-Wiley.

Ramadier, T., \& Enaux, C. (2012). L'accessibilité socio-cognitive. In P. Frankhauser \& D. Ansel (Eds.), La décision d'habiter ici ou ailleurs (pp. 76-101). Economica.

Rapoport, A. (1969). House form and culture. Englewood Cliffs: Prentice Hall.

Rouquette, M-L. (2006). Introduction. In K. Weiss \& D. Marchand (Eds.), Psychologie sociale de l'environnement (pp. 11- 16). Rennes: Presses Universitaires de Rennes.

Ross, L., Greene, D., \& House, P. (1977). The "false consensus effect": An egocentric bias in social perception and attribution processes. Journal of Experimental Social Psychology, 13(3), 279-301.

Simon, H. (1947). Administrative Behavior. New York, NY: Macmillan.

Slater, P. (Ed.) (1976). Exploration of intrapersonal space, 2 vol. London: Wiley.

Stevens, H. (2011). De l'intervention psychosociologique au "développement personnel" dans l'entreprise. Esquisse d'une généalogie des relations entre management et psychologie en France. Regards Sociologiques, 41/42, 57-74.

Stokols, D. (1972). On the distinction between density and crowding: some implications for future research. Psychological Review, 79(3), 275-277. 
Stokols, D. (1978). Environmental psychology. Annual Review of Psychology, 29, 253-295.

Stokols, D. (1987). Conceptual strategies of environmental psychology. In D. Stokols, \& I. Altman (Eds.), Handbook of environmental psychology (pp. 41-70). New York: John Wiley \& Sons.

Stokols, D. (1990). Instrumental and Spiritual Views of People-Environment Relations. American Psychologist, 45(5), 641-646.

Stoop, J. R. (1935). Studies of interference in serial verbal reactions. Journal of Experimental Psychology, 18, 643-662.

Tafani, E., \& Bellon, S., (2001). Principe d'homologie structurale et dynamique représentationnelle. In P. Moliner (Ed.), La dynamique des représentations sociales (pp. 163-193). Grenoble: Presses universitaires de Grenoble.

Tversky, A., \& Kahneman, D. (1981). The framing of decisions and the Psychology of choice. Science, 211, 453-458.

Uzzell, D., \& Moser, G. (2006). On the quality of life of environment. European Review of Applied Psychology, 56(1), 1-4.

Viaud, J. (2003). Positions sociales et représentations: contribution d'un cas de mobilité sociale ascendante à l'étude des dynamiques représentationnelles. Cahiers internationaux de psychologie sociale, 58, 39-49.

Wacquant, L., (1992). Introduction. In P. Bourdieu \& L. Wacquant (Eds.). Réponses. Pour une anthropologie réflexive. Paris: Seuil.

Wicker, A. W. (1973). Undermanning theory and research: implications for the study of psychological and behavior effects of excess populations. Representative Research in Social Psychology, 4, 185-206.

Wicker, A. W. (1979). An introduction to ecological psychology. Monterey: Brooks and Cole Publishing Company.

Wohlwill, J. F. (1970). The emerging discipline of environmental psychology. American Psychologist, 25(4), 303-312. 